\title{
SAVING THE
}

North Atlantic

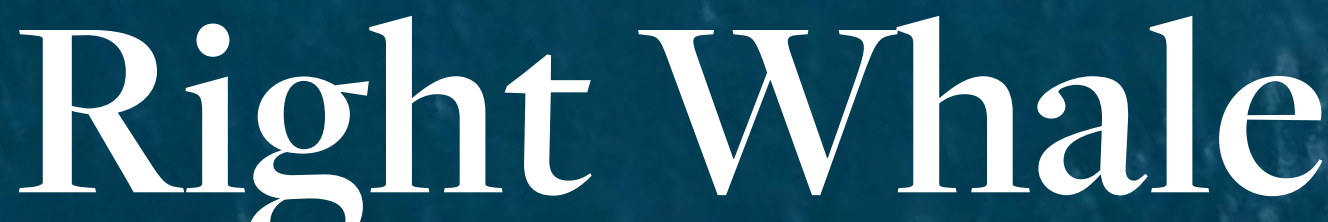

Produced in collaboration with

marine biologists Michael Moore and Mark Baumgartner, Woods Hole Oceanographic Institution 
The North Atlantic right whale is one of the most endangered whales in the world. Only about 411 remain. This report from Woods Hole Oceanographic Institution (WHOI) examines the top three threats facing the North Atlantic right whale and explores actions being taken by the scientific community and concerned organizations to ensure the long-term survival of this critically endangered species.

\section{North Atlantic Right Whales in Crisis}

The North Atlantic right whale (Eubalaena glacialis) is a critically endangered whale species that is protected under the U.S. Endangered Species Act, the Marine Mammal Protection Act, and Canada's Species at Risk Act. These animals are often found within 50 miles of the East Coast of North America, making them vulnerable to human activities.

Whaling for the North Atlantic right whale became illegal in 1935, when the species was close to extinction. By 1992, an estimated 295 were alive. ${ }^{1}$ Growth in North Atlantic right whale numbers averaged 2.8 percent per year between 1990 and 2010, ${ }^{2}$ which brought the population up to roughly 500 by $2010 .{ }^{3}$ However, calving rates have dropped by nearly 40 percent since then, and over the last four decades an increasing number of North Atlantic right whales have been killed by collisions with ships.4, 5, 6 Ship collisions and entanglements in fishing gear continue to contribute substantially to the species' decline.

Why aren't they flourishing?

An aerial view of an adult North Atlantic Right Whale and calf. Photo: WHOI, NOAA Permit \#17355
The purpose of this report is to explore the top three critical threats facing the North Atlantic right whale: fishing gear entanglements, vessel collisions, and noise pollution. Importantly, this report will also focus on the crucial efforts underway to develop the most effective and pragmatic solutions for addressing these risks and supporting the recovery of the North Atlantic right whale population. 


\section{Whale Entanglements}

\section{The Problem}

In trap/pot fisheries that target lobster, crab, and fish along the U.S. and Canadian eastern seaboards, fishermen use long vertical ropes or "lines" that connect traps on the ocean bottom to floats on the water surface-a system that allows fishermen to locate their traps and haul them back up. These ropes, which are suspended in the water column, pose a critical danger to North Atlantic right whales as whales are easily entangled in the lines and have no means of escape.

Whales that become entangled will often drag the heavy gear around for months, expending more energy and gradually losing weight. The ropes constrict body parts, impair the ability to feed, and can slice into flesh and bone-causing abrasions, infections, and sometimes partial amputations. Whales snarled in gear can have

\section{A tangled web} When a whale becomes entangled, fishing gear can cut into its flesh, impede its ability to dive and feed, and create a drag that exhausts its energy supply. Photo: EcoHealth Alliance, NOAA Fisheries Permit \#594-1759 trouble swimming, diving, and breathing, and those that survive may not have the energy reserves needed to reproduce.

Research suggests that fishing gear entanglements are becoming increasingly critical. From 2010 to 2015, 85 percent of diagnosed North Atlantic right whale deaths were due to entanglements. ${ }^{78}$ And despite efforts to reduce accidental kills of whales in fishing gear, both nonfatal and lethal entanglement rates have increased..$^{9,10,11} \mathrm{~A}$ study that examined all available photographs of North Atlantic right whales taken from 1980 to 2009 found that out of 626 individual whales, 83 percent showed scars caused by ropes or nets, and 59 percent had been entangled more than once. ${ }^{12}$






\section{Diagnosed North Atlantic right whale deaths}



\section{Solutions}

\section{ROPELESS FISHING GEAR}

Ropeless fishing technology presents a possible solution that could be both safe for the North Atlantic right whale and viable for the Atlantic fishing industry. Several prototypes are currently under development and some fishermen are partnering with scientists to test different ropeless fishing traps.

One device that is currently used commercially in Australia replaces the static line in the water column with a coiled rope and buoy that are inside a weighted bag attached to the trap on the ocean bottom. Fishermen can send a signal to the trap, which triggers an acoustic release, sending the buoy and rope floating to the surface where they are immediately hauled aboard.

Another ropeless technology is based on an inflatable buoy that is attached to the trap. An acoustic trigger inflates the buoy, which rises with the trap to the surface. Although not yet adopted in North America, these two options are being tested in both U.S. and Canadian waters.

\section{Going ropeless}

WHOI engineers have developed a patentpending ropeless technology that uses an acoustic signal to release a line from a trap. Engineers have completed onshore testing of the prototype hardware with successful results, clearing the way to move forward with atsea trials. The results of these tests, including feedback from fishermen, should allow the engineers to revisit the design of the hardware to improve usability and manufacturability. Illustration: Eric Taylor, WHOI Creative

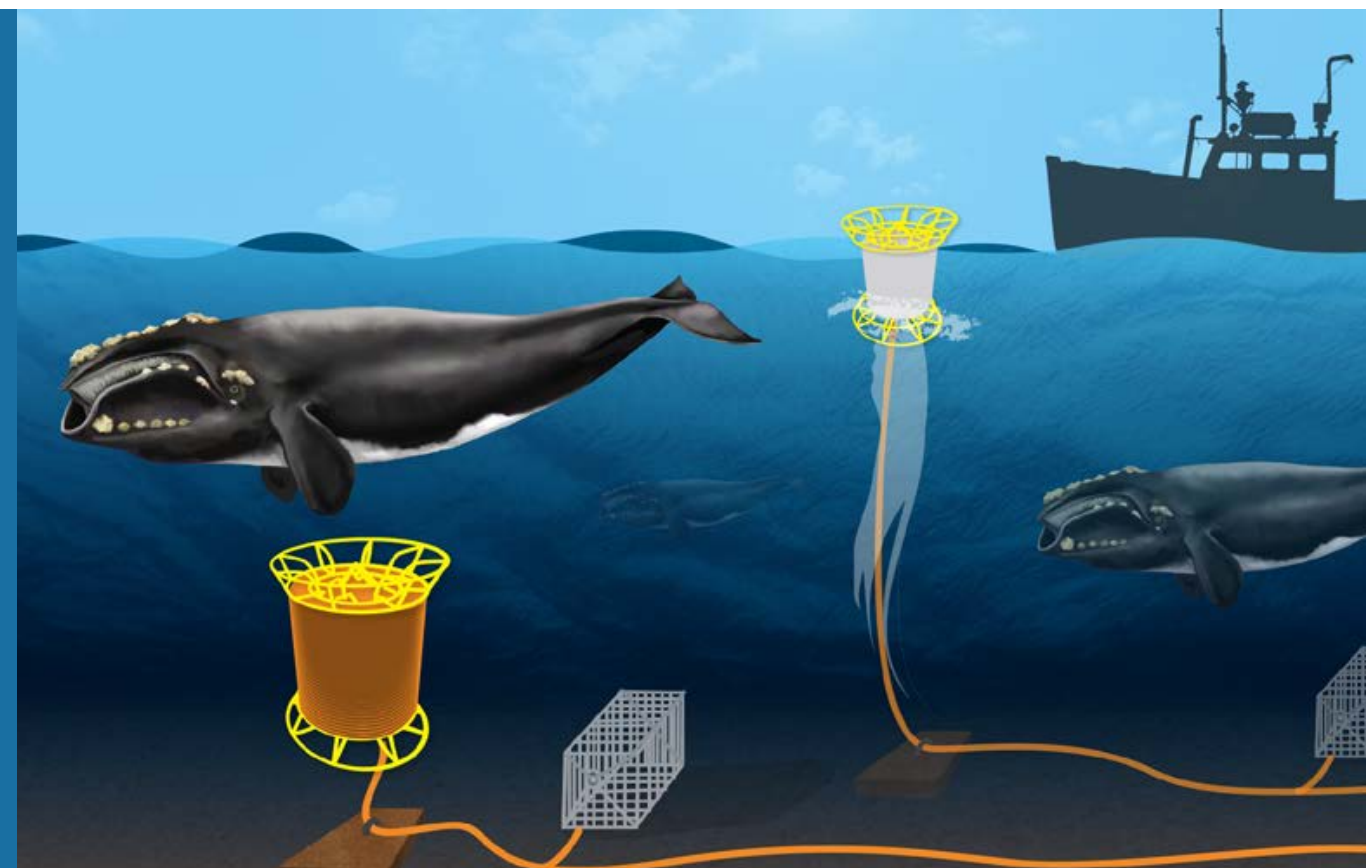




\section{DISENTANGLEMENT EFFORTS}

Disentanglement efforts have been successful at freeing hundreds of large whales that have become caught in fishing gear. Disentanglement operations along the East Coast of the U.S. are spearheaded by the Atlantic Large Whale Disentanglement Network, which comprises highly-trained emergency responders from 20 public and private organizations.

Removing fishing lines that are wrapped around the whales is both challenging and dangerous. Teams approach the whales in small inflatable boats use grappling hooks to grasp the tangled gear. Buoys that can be easily removed are then attached to the fishing lines to slow the whales down, allowing the rescuers to move closer. Once they are within reach, the disentanglement team uses a custom-designed tool attached to a long pole to cut away the fishing gear. After the whale is disentangled, the team again uses the grappling hooks to remove the debris from the water.

North Atlantic right whales, in particular, can be harder to disentangle than other whales due to their strength, endurance, and their need for more personal space, which often makes them more difficult to approach.

\section{Sedation technique for whale disentanglement}

An experimental approach for disentangling ensnared North Atlantic right whales that cannot be freed any other way involves using drugs to render them less evasive and not so bothered by an approaching boat, which enables teams to more easily cut them free. However, medicating these large whales at sea presents challenges. They need to be able to continue to swim and breathe. Rescue teams must balance the risks of underdosing and overdosing. WHOI is currently collaborating to develop this technique further.

\section{A noose in the}

\section{deep blue}

A disentanglement team attempts to free a right whale from fishing gear. Photo: EcoHealthAlliance, NOAA Permit \#932-1905. 


\section{COMPUTER MODELING}

Evidence suggests that most North Atlantic right whales become entangled in fishing gear at some point in their lives. However, little documentation is available that shows how entanglement happens when the whales encounter fishing gear. To better understand how entanglement occurs, scientists from BelleQuant Engineering, Duke University, and the Anderson Cabot Center for Ocean Life at the New England Aquarium collaborated on the development of a simulator that recreates whale entanglements. Users navigate a virtual whale through a water column containing fishing gear, allowing scientists to study how North Atlantic right whales move and react when encountering different types of fishing gear configurations. ${ }^{16}$

The simulated North Atlantic right whale model was designed based on a morphologically accurate representation with realistic swimming motions. The goal of the simulator is to develop a better understanding of the dynamics of entanglement to help prevent it from happening. By recreating the way ropes wrap around North Atlantic right whales, scientists hope to determine how to change fishing gear to reduce entanglement risks.

\section{REDUCED-BREAKING-STRENGTH ROPE}

A possible near-term solution to address fishing gear entanglement is the use of reduced-strength lines that break more easily. Although entanglements may not be prevented, the number of injuries and deaths could be reduced if North Atlantic right whales were better able to break free from entangling ropes. ${ }^{11}$ Reduced-strength ropes offer the added advantage of preserving the fishing industry's current fishing methods.

\section{WHALE-SAFE LABELING}

As a strategy to help incentivize more widespread adoption of ropeless fishing gear for reducing entanglements, efforts are underway to include ropeless fishing technologies with certification programs and whale-safe labeling that recognizes sustainable practices within wild-capture fisheries and aquaculture operations. These efforts also extend to nongovernmental organization seafood ratings, which acknowledge whether seafood was caught using fishing practices that cause little harm to habitats or other wildlife. 


\section{Vessel Collisions}

\section{The Problem}

Another major threat to the survival of the North Atlantic right whale is injuries resulting from vessel collisions. Right whales can be found all along the coast between Florida and eastern Canada near major ports and numerous shipping lanes, which makes the whales susceptible to vessel strikes.

From 1970 to 2009, vessel strikes were the leading cause of diagnosed North Atlantic right whale mortalities. ${ }^{17}$ Between 2002 and 2006 alone, the U.S. National Marine Fisheries Service (NMFS) confirmed that 10 North Atlantic right whales were killed and 2 severely injured by vessel collisions. Many more collisions go undetected.

In 1999, coastal managers began to systematically use planes and boats to spot North Atlantic right whales so they could give advisories to vessels. But these methods can't be used at night or in bad weather. Nor can they find whales when they aren't swimming near the surface.

\section{Solutions}

\section{WHALE DETECTION BUOYS}

To help vessels avoid lethal collisions with endangered North Atlantic right whales, WHOI biologists and engineers have developed an acoustic buoy to make near realtime detections of whales in areas near shipping lanes. Known as a digital acoustic

A buoy that listens DMON (Digital acoustic MONitoring) buoys detect whale calls and transmit information about them from the seafloor up the cable to the buoy, which relays the information to a satellite and ultimately to scientists in near-real time. Illustration: Eric Taylor, WHOI Creative monitoring (DMON) instrument, the device sits in a weighted frame at the bottom of the ocean and is equipped with underwater microphones called hydrophones that listen for whale sounds.

Information about detected sounds is transmitted through a stretchable hose up to a buoy on the surface and sent via satellite to a lab at WHOI. The data is then reviewed by an analyst and posted on the publicly-accessible website robots4whales.whoi.edu. For several years, the acoustic buoy has successfully detected whales in near real-time off the Massachusetts and New York coasts, alerting regulators, scientists, and the shipping industry about the presence of whales. 


\section{VESSEL SPEED RESTRICTIONS}

As a regulatory action to reduce the likelihood of lethal vessel strikes to North Atlantic right whales, NMFS and NOAA in 2008 enacted a series of vessel speed restrictions for vessels in certain areas along the U.S. East Coast. According to the restrictions, all vessels 65 feet (19.8 meters) or longer must travel at 10 knots or less in Seasonal Management Areas along the U.S. Atlantic seaboard at certain times of the year. The 10-knot speed restriction also extends out to 20 nautical miles around major mid-Atlantic ports. Since the regulations were implemented, deaths from vessel strikes have declined. ${ }^{18,19}$

\section{VESSEL ROUTING RECOMMENDATIONS}

Several regulatory measures have been implemented to route vessels in a manner that reduces the probability of collisions. Beginning in 2001, NMFS, in cooperation with the U.S. Coast Guard, began developing a vessel-strike reduction strategy that was mainly based on routing vessels through areas where North Atlantic right whales were less likely to be. The first measure implemented in the U.S. under the strategy was the designation of new shipping lanes off ports adjacent to the right whale calving grounds in $2006 .{ }^{20}$

Other regulations to route vessels for protecting the North Atlantic right whale include:

- In 2003, the International Maritime Organization moved shipping lanes in the Bay of Fundy away from an area with the highest density of North Atlantic right whales to an area of lower density.

- In 2006, NOAA established a set of recommended vessel routes to reduce vessel strikes in four important Eastern U.S. right whale habitats.

- In 2007, and again in 2009, NOAA changed the Traffic Separation Scheme (i.e., shipping lanes) servicing Boston to reduce vessel collisions with right whales and other whale species.

- In 2009, NOAA designated certain waters in the Great South Channel off Cape Cod as an "Area to Be Avoided" by vessels.

- The Roseway Basin "Area to be Avoided" region in Canada.

Huge threat Right whales are found all along the eastern seaboards of the U.S. and Canada, making them susceptible to vessel strikes. Photo: iStock.

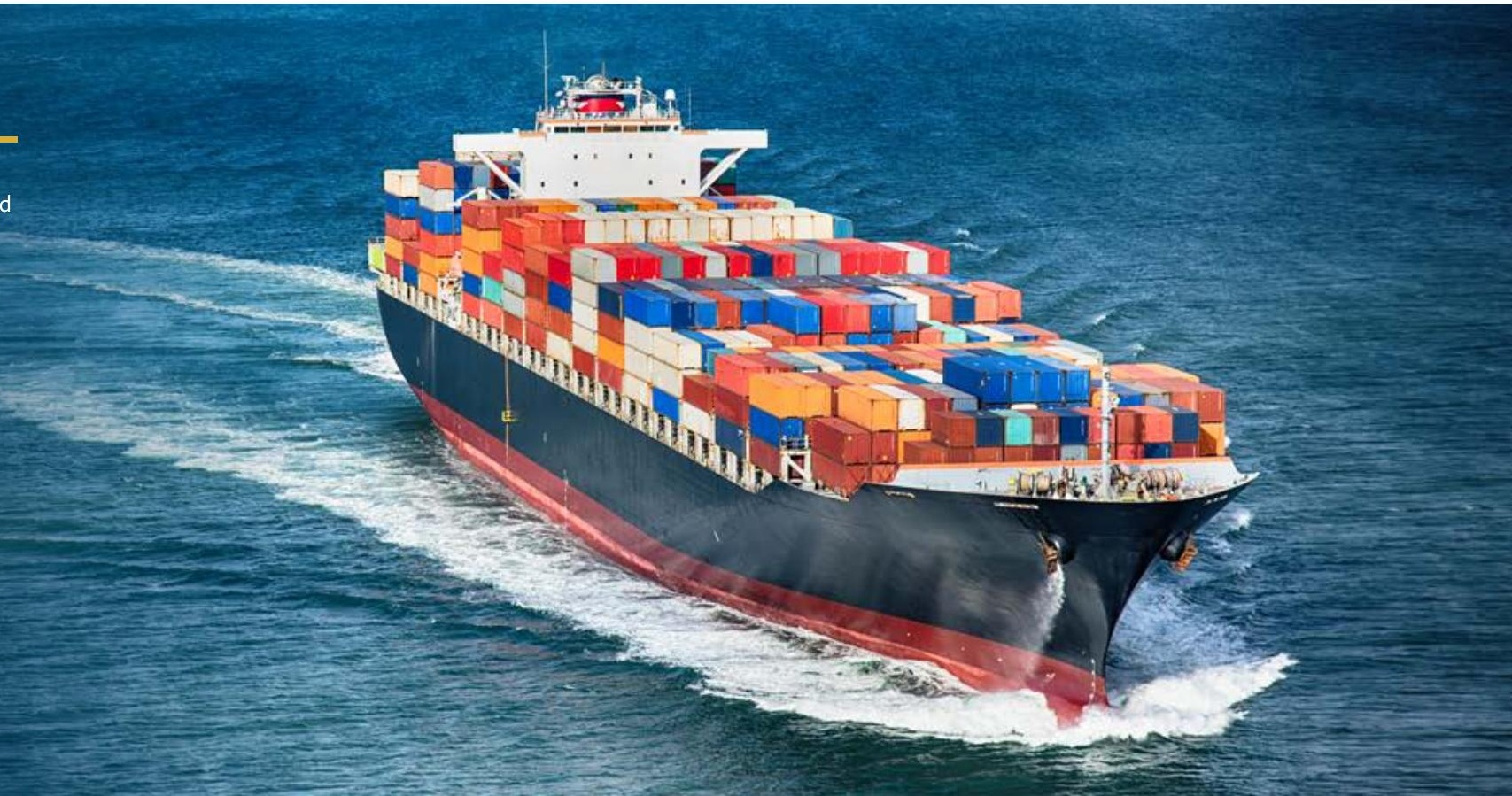


A possible alternative to seismic air guns is marine Vibroseis, which has been used successfully in land-based seismic exploration for many years. ${ }^{24}$ Instead of a sharponset, loud, intense "shot," Vibroseis uses the same energy but spread over a longer duration, thus eliminating the sharp rise time (sounds quickly increasing in loudness) and high peak pressure (volume or amplitude) of air guns-two characteristics of sound thought to be the most injurious to living tissues. ${ }^{25}$

The acoustic footprint, as measured in terms of both peak pressure and sound exposure level, is substantially smaller for marine Vibroseis than that of air guns for the same geophysically useful energy output, providing an environmentally safer alternative to air guns without compromising effectiveness for seismic exploration. ${ }^{26}$

\section{QUIETING VESSEL ENGINES}

Vessel-quieting technologies and solutions are available to help reduce the underwater noise continually generated by the propellers, motors, and gears of large commercial vessels. Propellers, which cause cavitation (formation and rapid collapse of bubbles), are the main source of underwater sound generated by vessels, but the shape of a vessel's hull can also influence propeller performance and the resulting noise production. Machinery onboard vessels-such as engines, turbines, and generators as well as where that machinery is located on the vessel-is also a factor that affects how sound emits from vessels to the surrounding waters.

Technologies such as low-noise propulsion systems-which use larger and slowerspinning propellers to minimize cavitation - and mounting systems that raise engines off the engine room floor to reduce vibration, have allowed NOAA to reduce the noise levels from some of their vessels. Vessels can also reduce the amount of machinery noise by using equipment with inherently low noise and vibration levels or by installing vibration isolators that use elastic materials within the machinery.

The International Maritime Organization has established guidelines for marine noise, but the guidelines are not mandatory. Turning these guidelines into mandates would represent a significant step forward. 


\section{How you can help}

NOAA Fisheries lists ways that the public can help save the North Atlantic right whale:

\section{Report a Right Whale Sighting}

Please report all right whale sightings from Virginia to Maine to (866) 755-6622, and from Florida to North Carolina to 877-WHALE-HELP ((877) 942-5343). Right whale sightings in any location may also be reported by ship radio to the U.S. Coast Guard via channel 16 or through the Whale Alert iPhone/iPad app.

\section{Stay 500 Yards Away}

To protect right whales, NOAA Fisheries has regulations that prohibit approaching or remaining within 500 yards $(1,500$ feet) of a right whale -500 yards is the length of five football fields. These regulations apply to vessels and aircraft (including drones), and to people using other watercraft such as surfboards, kayaks, and Jet Skis. Any vessel within 500 yards of a right whale must depart immediately at a safe, slow speed.

\section{Report Marine Life in Distress}

Report a sick, injured, entangled, stranded, or dead animal to make sure professional responders and scientists know about it and can take appropriate action. Numerous organizations around the country are trained and ready to respond. These include:

- Northeast Marine Mammal and Sea Turtle Stranding and Entanglement Hotline: (866) 755-6622

- NOAA Fisheries Southeast Marine Mammal Stranding Hotline (877) 942-5343

\section{Report a Violation}

Call the NOAA Fisheries Enforcement Hotline at (800) 853-1964 to report a federal marine resource violation. This hotline is available 24 hours a day, seven days week for anyone in the United States.

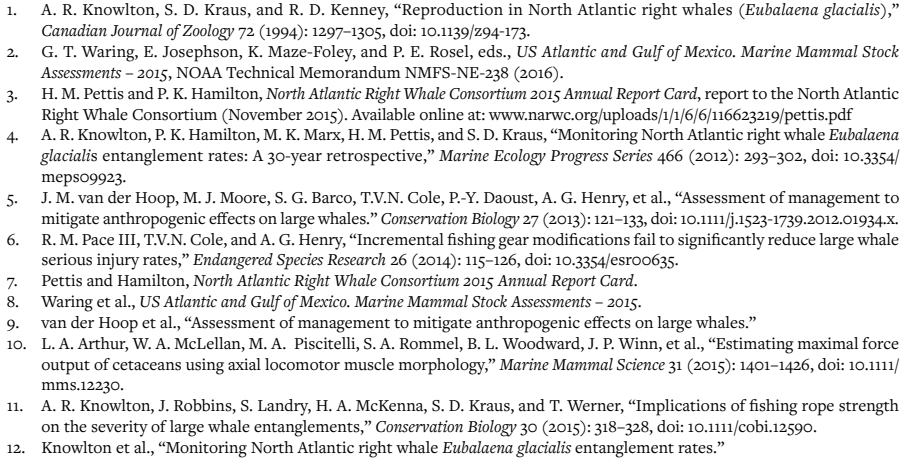

13. van der Hoop et al., "Assessment of management to mitigate anthropogenic effects on large whales."

14. Pettis and Hamilton, North Atlantic Right Whale Consortium 2015 Annual Report Card.

Waring et al, US Atlantic and Gulf of Mexico. Marine Mammal Stock Assessments.

5. Waring et al., US Atlantic and Gulf of Mexico. Marine Mammal Stock Assessments.
6. Howle, Laurens E., Scott D. Kraus, Timothy B. Werner, and Douglas P. Nowacek. "Simulation of the entanglement of a North Atlantic right whale (Eubalaena glacialis) with fixed fishing gear." Marine Mammal Science (2018).

. van der Hoop et al., "Assessment of management to mitigate anthropogenic effects on large whales,"

D. W. Laist, A. R. Knowlton, and D. Pendleton, "Effectiveness of mandatory vessel speed limits for protecting North Atlantic right whales," Endangered Species Research 23 (2014): 133-147, doi: 10.3354/esroos86.

. J. M. van der Hoop, A.S.M. Vanderlaan, T.V.N. Cole, A. G. Henry, L. Hall, B. Mase-Guthrie, et al., "Vessel strikes to large whales before and after the 2008 Ship Strike Rule," Conservation Letters 8 (2015): 24-32, doi: 10.1111/conl.12105.

o. Marine Mammal Commission, Ship Strikes and Right Whales, October 2015.

21. Right Whale Listening Network, Bioacoustics Research Program. The Cornell Lab of Ornithology.

22. M. R. Rolland, S. E. Parks, et al., "Evidence that ship noise increases stress in right whales," Proceedings of the Royal Societ B. Volume 279, Issue 1737 (2012).

3. S. L. Nieukirk, D. K. Mellinger, S. E. Moore, et al. (2012), "Sounds from airguns and fin whales recorded in the mid-Atlantic Ocean, 1999-2009," Journal of the Acoustical Society of America 131 (2012): 1102-12

. L. Weilgart, Alternative Quieting Technology to Seismic Airguns for Oil \& Gas Exploration and Geophysical Research, brief for Global Sustainable Development Report - 2016 Update (2016).

25. B. L. Southall et al., "Marine mammal noise exposure criteria: initial scientific recommendations," Aquatic Mammals 33 (4) (2007): 411-522.

26. Weilgart, Alternative Quieting Technology. 


\section{Woods Hole
oceanographic}

Woods Hole Oceanographic Institution is dedicated to advancing our knowledge of the ocean. For our planet and our future.

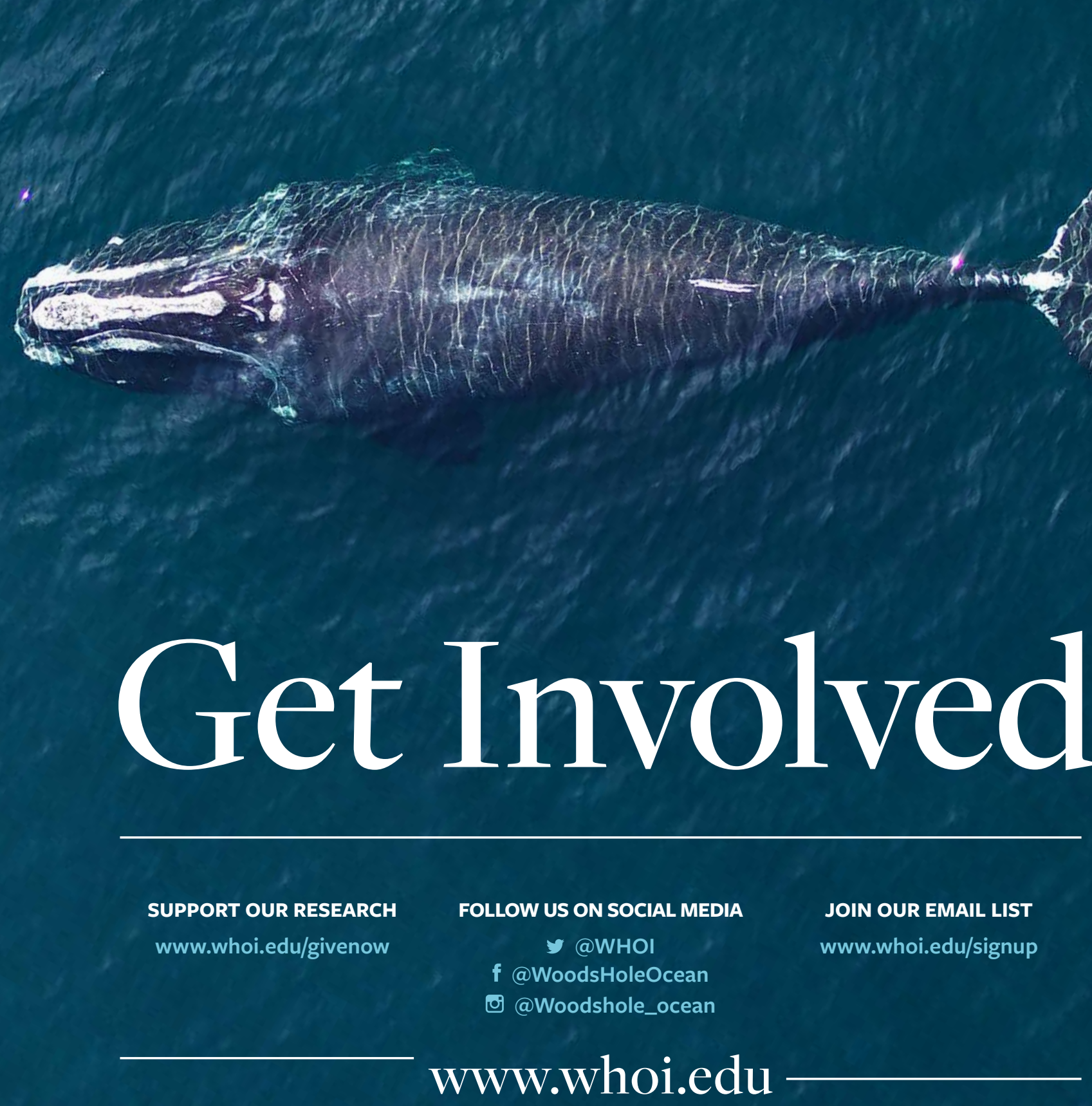

Woods Hole Oceanographic Institution. 2019. Saving the North Atlantic Right Whale. Produced in Collaboration with Michael Moore and Mark Baumgartner, Woods Hole Oceanographic Institution. Woods Hole (MA): WHOI, 12 pp. DOI 10.1575/1912/24708 